\title{
Acceptance of a vaccine against COVID-19 - a systematic review of surveys conducted worldwide
}

\author{
Snehota $\mathrm{M}^{1,2}$, Vlckova $\mathrm{J}^{3}$, Cizkova $\mathrm{K}^{4}$, Vachutka $\mathrm{J}^{1}$, Kolarova $\mathrm{H}^{1,5}$, Klaskova $\mathrm{E}^{2}$, Kollarova $\mathrm{H}^{3}$ \\ Department of Medical Biophysics, Faculty of Medicine and Dentistry, Palacky University Olomouc, \\ Olomouc, Czech Republic. martin.snehota@upol.cz
}

\begin{abstract}
OBJECTIVES: The most promising strategy for managing COVID-19 pandemic is achieving sufficient vaccination rate worldwide. The question is how many people will be willing to get vaccinated.

STUDY DESIGN: We systematically reviewed peer-reviewed manuscripts monitoring people's intention to receive a vaccine against COVID-19.

METHODS: Up to December 28, 2020 we identified 62 relevant peer-reviewed articles in PubMed, Web of Science, Scopus and GoogleScholar.

RESULTS: Total sample size was 118855 respondents with overall average COVID-19 vaccine acceptance rate of $72.5 \%$ which is "just" the level estimated to be sufficient for reaching herd immunity threshold. Surprisingly, healthcare workers showed smaller interest in receiving the vaccine when compared to general adult population and university students. On the other hand, their attitude to vaccination did not change over time. In case of general adult population, the longer the pandemic lasts, the smaller proportion of population wants to get vaccinated. Vaccination intentions were independent of gross domestic product and human development index.

CONCLUSION: Willingness of population to receive COVID-19 is just at the herd immunity threshold and it is decreasing over time (Tab. 2, Fig. 3, Ref. 110). Text in PDF www.elis.sk KEY WORDS: vaccination, survey, COVID-19, pandemic, review.
\end{abstract}

\section{Introduction}

A lot of work has been done in the field of vaccination since 1796, when Edward Jenner performed the first internationally recognized vaccination. Most of the progress has been made especially in 20 th and 21 st century when scientific advances in microbiology and immunology enabled targeted vaccine development (1-3). Unfortunately, despite undisputable benefits of vaccination (4) conspiracy theories concerning vaccination have emerged and resulted in increasing vaccine hesitancy worldwide (5). Vaccine hesitancy is defined as delay in acceptance or refusal of vaccina-

${ }^{1}$ Department of Medical Biophysics, Faculty of Medicine and Dentistry, Palacky University Olomouc, Olomouc, Czech Republic, ${ }^{2} \mathrm{Center}$ for Telemedicine, Simulation and Clinical Skills. Faculty of Medicine and Dentistry, Palacky University Olomouc, Olomouc, Czech Republic, ${ }^{3}$ Department of Public Health, Faculty of Medicine and Dentistry, Palacky University Olomouc, Olomouc, Czech Republic, ${ }^{4}$ Department of Histology and Embryology, Faculty of Medicine and Dentistry, Palacky University Olomouc, Olomouc, Czech Republic, and 5 Institute of Molecular and Translational Medicine, Faculty of Medicine and Dentistry, Palacky University Olomouc, Olomouc, Czech Republic

Address for correspondence: M. Snehota, MD, Department of Medical Biophysics, Faculty of Medicine and Dentistry, Palacky University Olomouc, Hnevotinska 3, CZ-775 15 Olomouc, Czech Republic.

Phone: +420.585 .632102$

Acknowledgements: This work was supported by the grant project IGA LF 2020_015 and by the European Regional Development Fund - Project ENOCH (No. CZ.02.1.01/0.0/0.0/16_019/0000868). tion despite availability of vaccination services (6). WHO (World Health Organization) enlisted vaccine hesitancy among top ten threats to global health in 2019 (7).

Vaccination rates against many vaccine-preventable diseases are considerably low in adults (8-10). For example, 50000-70000 adults die of vaccine-preventable diseases in United States of America every year (11). Several campaigns and initiatives such as ADVICE (Adult Vaccination Campaign in Europe) or Healthy People 2020 try to improve vaccination rates worldwide $(12,13)$. Official webpages of organizations such as WHO (World Health Organization) or CDC (Centers for Disease Control and Prevention) spend considerable room for explanation of benefits of vaccination $(14,15)$.

The topic of vaccination has gained enormous public interest during 2020 due to spread of COVID-19.

COVID-19 started in late 2019 in Wuhan, China and since then it spread worldwide. On 11.3.2020 WHO made the assessment that COVID-19 can be characterized as a pandemic (16). The infection primarily affects respiratory tract (17) ranging from asymptomatic course of the disease up to very severe health conditions requiring hospitalization at intensive care unit (18). COVID-19 may not only affect respiratory tract but may also result in hepatic, cardiac, renal, gastrointestinal, neurologic and musculoskeletal complications (19-26). The most effective long-term strategy for prevention of future outbreaks of the novel coronavirus is the development of a vaccine (27). During 2020 many pharmaceutical companies, universities and scientists all over the world attempted to create a safe and effective vaccine against COVID-19. In December 2020 
the U.S. Food and Drug Administration issued an emergency use authorization for the Pfizer-BioNTech COVID-19 vaccine and also for the Moderna COVID-19 vaccine (28). In late 2020 and early January 2021 many countries worldwide started to vaccinate their citizens, usually starting with healthcare professionals. The question is: What will be the acceptance rate of COVID-19 vaccine across global population?

\section{Aim}

The main aim of this work is to systematically search for studies covering the intentions of people to receive a vaccine against COVID-19 according to PRISMA (Preferred Reporting Items for Systematic Reviews and Meta-analyses) statement (29). Only the studies that had undergone peer-review process will be assessed.

\section{Methods}

\section{Searching for relevant articles}

The search was conducted on December 28, 2020 in English. We searched for relevant articles in PubMed ${ }^{\circledR}$, Web of Science and Scopus databases. The searching strategy was following: (covid*[Title/Abstract] OR corona*[Title/Abstract] OR SARS*[Title/Abstract]) AND vaccin*[Title/Abstract] AND (survey*[Title/Abstract] OR question*[Title/Abstract] OR opinion*[Title/Abstract] OR attit*[Title/Abstract]). The results were restricted to year range 2019-2020 (2021 respectively). Additional searching with aforementioned key words was also conducted in GoogleScholar.

\section{Result synthesis}

Results of searching from PubMed ${ }^{\circledR}$, Web of Science and Scopus were exported in BibTex format and imported to Mendeley Desktop software. Duplicities were removed.
Eligibility criteria for inclusion of studies to this review

Eligibility of studies was assessed at two levels. Firstly, we went through a title and abstract of each article. Articles that were excluded at this level mainly covered biological experiments and e-learning topics. Also, the articles that obviously did not use any type of survey methods were excluded. In case of any hesitancy, particular manuscript was forwarded to the next level of assessment.

For the second level of assessment we acquired full-text version of all articles that passed the first level. Among these (detailed PRISMA Flow Diagram is shown in results) we looked for the ones covering the intentions of people to receive a vaccine against COVID-19 for themselves. The ones asking for example parents if they would have their children vaccinated against COVID-19 were excluded. Several articles assessed people's willingness to pay for a COVID-19 vaccine. These articles were included in our work (marked as "wtp" note in Table 1). Also, the articles designed as discrete choice experiments and the ones giving irrelevant data on the acceptability of COVID-19 vaccine (mainly the ones showing just the correlations between COVID-19 vaccine acceptance and other factors and also the ones giving just the average of values on various Likert scales in absence of any supplementary data) were excluded.

In few cases the same data were published in more than one manuscript. In such case only one of these works was included in the analysis.

Only the articles that underwent full peer-review process were included in this work. Preprints that had not undergone peer-review process yet were excluded.

Anytime necessary we further searched for supplementary materials and appendices of particular manuscripts.

\section{Analysis of articles included in this work}

Each article that passed both levels of eligibility assessment was analysed and following information were extracted: country

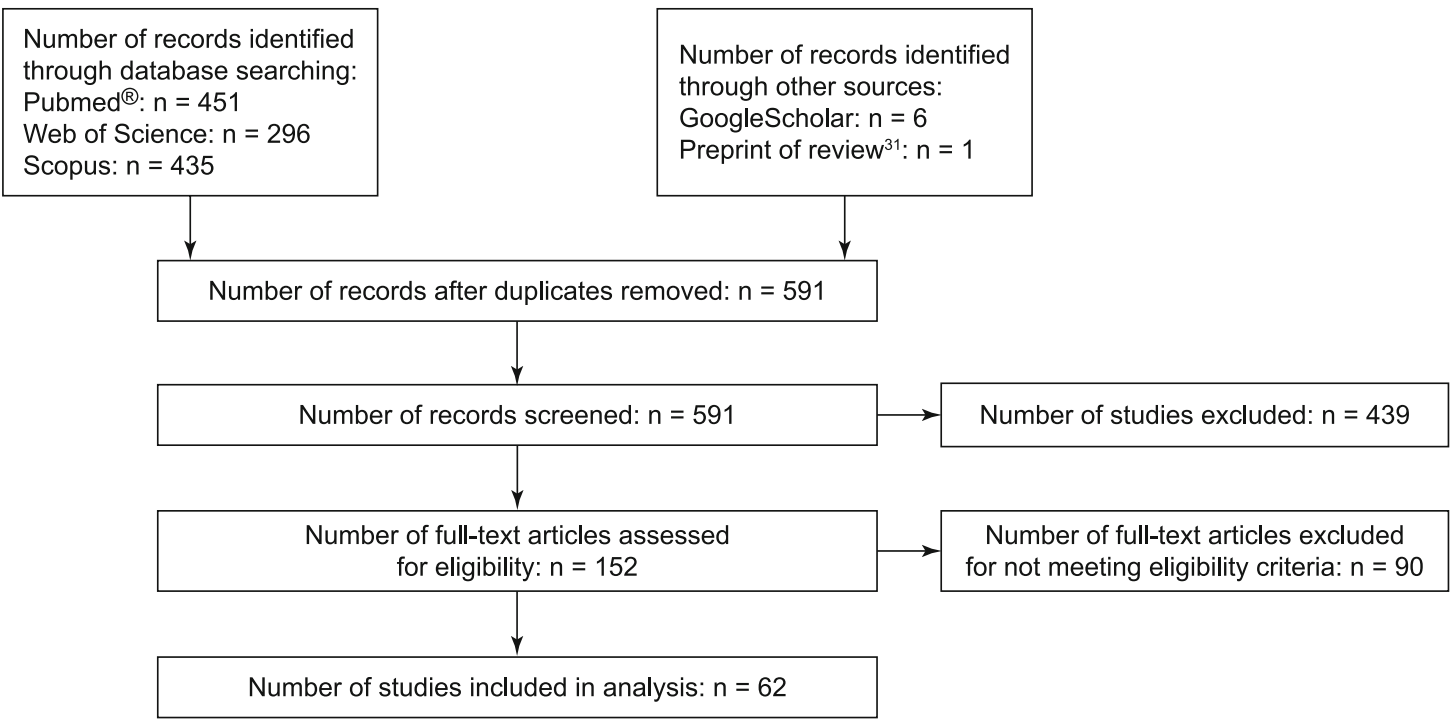

Fig. 1. PRISMA Flow Diagram. 
Tab. 1. Summary of all 62 identified studies.

\begin{tabular}{|c|c|c|c|c|c|c|}
\hline Note & Country & Time & Population & $\begin{array}{l}\text { Number of } \\
\text { respondents }\end{array}$ & $\begin{array}{c}\text { Vaccine } \\
\text { acceptance }\end{array}$ & Source \\
\hline & $\begin{array}{l}\text { Arabian Gulf Countries } \\
\text { (Bahrain, Kuwait, Saudi } \\
\text { Arabia, United Arab Emirates) }\end{array}$ & 28.3.2020-4.4.2020 & general adult & 5677 & $72.0 \%$ & $(56)$ \\
\hline & Australia & $2.3 .2020-9.3 .2020$ & general adult & 2174 & $81.1 \%$ & $(57)$ \\
\hline \multirow[t]{2}{*}{ A } & Brazil & 16.6.2020-20.6.2020 & general adult & 717 & $85.4 \%$ & (58) \\
\hline & Canada & $6.5 .2020-19.5 .2020$ & general adult & 1902 & $80.0 \%$ & (59) \\
\hline \multirow[t]{2}{*}{ A } & Canada & 16.6.2020-20.6.2020 & general adult & 707 & $68.7 \%$ & (58) \\
\hline & Congo & $20.3 .2020-30.4 .2020$ & hcw & 613 & $27.7 \%$ & $(48)$ \\
\hline $\mathrm{B}$ & Denmark & $2.4 .2020-15.4 .2020$ & general adult & $\approx 1000$ & $80.0 \%$ & $(60)$ \\
\hline wtp & Ecuador & $2.4 .2020-7.4 .2020$ & general adult & 972 & $85.0 \%$ & $(61)$ \\
\hline \multirow[t]{2}{*}{ A } & Ecuador & 16.6.2020-20.6.2020 & general adult & 741 & $71.9 \%$ & (58) \\
\hline & Egypt & March 2020 & general adult & 559 & $88.6 \%$ & $(62)$ \\
\hline $\mathrm{C}$ & Finland & $30.3 .2020-12.4 .2020$ & general adult & 194 & $77.8 \%$ & (63) \\
\hline $\mathrm{C}$ & Finland & $3.4 .2020-17.4 .2020$ & general adult & 1319 & $72.9 \%$ & (63) \\
\hline \multirow[t]{3}{*}{$\mathrm{C}$} & Finland & May 2020 & parents & 780 & $73.9 \%$ & (63) \\
\hline & France & 26.3.2020-20.4.2020 & general adult & 3259 & $77.6 \%$ & (64) \\
\hline & France & $26.3 .2020-2.7 .2020$ & hcw & 2047 & $76.9 \%$ & (65) \\
\hline $\mathrm{B}$ & France & $2.4 .2020-15.4 .2020$ & general adult & $\approx 1000$ & $62.0 \%$ & $(60)$ \\
\hline \multirow[t]{2}{*}{ A } & France & 16.6.2020-20.6.2020 & general adult & 669 & $58.9 \%$ & (58) \\
\hline & Germany & $27.3 .2020-11.4 .2020$ & hcw & 2827 & $91.1 \%$ & $(66)$ \\
\hline $\mathrm{B}$ & Germany & $2.4 .2020-15.4 .2020$ & general adult & $\approx 1000$ & $70.0 \%$ & (60) \\
\hline $\mathrm{D}$ & Germany & $18.5 .2020-2.8 .2020$ & hcw & 213 & $83.1 \%$ & (67) \\
\hline $\mathrm{D}$ & Germany & $18.5 .2020-2.8 .2020$ & university students & 1457 & $84.8 \%$ & (67) \\
\hline \multirow[t]{3}{*}{$\mathrm{A}$} & Germany & 16.6.2020-20.6.2020 & general adult & 722 & $68.4 \%$ & $(58)$ \\
\hline & Greece & $10.2 .2020-25.2 .2020$ & hcw & 461 & $43.3 \%$ & (49) \\
\hline & Greece & 15.4.2020-2.5.2020 & general adult & 1811 & $81.1 \%$ & $(68)$ \\
\hline \multirow[t]{6}{*}{ wtp } & Chile & $18.4 .2020-5.5 .2020$ & general adult & 566 & $90.6 \%$ & (69) \\
\hline & China & 10.02 .2020 & university students & 472 & $92.0 \%$ & $(70)$ \\
\hline & China & $26.2 .2020-31.3 .2020$ & hcw (nurses) & 806 & $40.0 \%$ & $(50)$ \\
\hline & China & 16.3.2020-29.4.2020 & hcw (nurses) & 1205 & $63.0 \%$ & $(71)$ \\
\hline & China & March 2020 & general adult & 2058 & $91.3 \%$ & $(72)$ \\
\hline & China & $1.5 .2020-19.5 .2020$ & general adult & 3541 & $83.5 \%$ & $(47)$ \\
\hline $\mathrm{A}$ & China & 16.6.2020-20.6.2020 & general adult & 712 & $88.6 \%$ & $(58)$ \\
\hline \multirow[t]{4}{*}{ A } & India & 16.6.2020-20.6.2020 & general adult & 742 & $74.5 \%$ & $(58)$ \\
\hline & India & $1.10 .2020-31.10 .2020$ & general adult & 351 & $86.3 \%$ & (73) \\
\hline & Indonesia & $25.3 .2020-6.4 .2020$ & general adult & 1359 & $93.2 \%$ & $(74)$ \\
\hline & Iran & $25.2 .2020-25.4 .2020$ & general (above 10 years of age) & 1480 & $73.2 \%$ & $(75)$ \\
\hline $\mathrm{E}$ & Israel & 26.3.2020-8.4.2020? & hcw & 549 & $71.5 \%$ & (76) \\
\hline \multirow[t]{2}{*}{$\mathrm{E}$} & Israel & 26.3.2020-8.4.2020? & general adult & 1112 & $75.0 \%$ & (76) \\
\hline & Italy & $27.2 .2020-8.3 .2020$ & general adult & 2223 & $70.4 \%$ & $(77)$ \\
\hline $\mathrm{B}$ & Italy (Lombardy) & $2.4 .2020-15.4 .2020$ & general adult & $\approx 500$ & $79.0 \%$ & $(60)$ \\
\hline \multirow[t]{4}{*}{$\mathrm{B}$} & Italy (not Lombardy) & $2.4 .2020-15.4 .2020$ & general adult & $\approx 1000$ & $74.0 \%$ & $(60)$ \\
\hline & Italy & April 2020 & general adult & 624 & $75.8 \%$ & $(78)$ \\
\hline & Italy & reopening after lockdown (May 2020) & general adult & 1004 & $58.6 \%$ & $(79)$ \\
\hline & Italy & $6.6 .2020-20.6 .2020$ & general adult & 885 & $92.0 \%$ & $(80)$ \\
\hline \multirow[t]{7}{*}{ A } & Italy & 16.6.2020-20.6.2020 & general adult & 736 & $70.8 \%$ & $(58)$ \\
\hline & Italy & $\mathrm{N} / \mathrm{A}$ & university students & 735 & $86.1 \%$ & $(81)$ \\
\hline & Italy & $16.9 .2020-28.9 .2020$ & general (above 15 years of age) & 1055 & $53.7 \%$ & $(82)$ \\
\hline & Jordan & 20.6.2020-25.7.2020 & $\begin{array}{l}\text { university students (medicine }+ \\
\text { dentistry) }\end{array}$ & 483 & $81.6 \%$ & (83) \\
\hline & Malaysia & $3.4 .2020-12.4 .2020$ & general adult & 1159 & $94.3 \%$ & $(84)$ \\
\hline & Malta & $11.9 .2020-16.9 .2020$ & hew & 1002 & $52.0 \%$ & $(51)$ \\
\hline & Malta & 16.9.2020-22.9.2020 & $\begin{array}{l}\text { university students }+ \text { staff of faculties of } \\
\text { medicine, dentistry and health sciences }\end{array}$ & 852 & $44.2 \%$ & $(85)$ \\
\hline
\end{tabular}




\begin{tabular}{|c|c|c|c|c|c|c|}
\hline Note & Country & Time & Population & $\begin{array}{l}\text { Number of } \\
\text { respondents }\end{array}$ & $\begin{array}{c}\text { Vaccine } \\
\text { acceptance }\end{array}$ & Source \\
\hline & Malta & 25.9.2020-29.9.2020 & $\begin{array}{c}\text { hcw (general practitioneers and } \\
\text { their trainees) }\end{array}$ & 123 & $61.8 \%$ & $(86)$ \\
\hline $\mathrm{F}$ & Mexico & April-May 2020 & general adult & 700 & $73.7 \%$ & $(87)$ \\
\hline \multirow[t]{2}{*}{ A } & Mexico & 16.6.2020-20.6.2020 & general adult & 699 & $76.2 \%$ & $(58)$ \\
\hline & Nepal & April-May 2020 & hew & 230 & $94.3 \%$ & $(88)$ \\
\hline $\mathrm{B}$ & Netherlands & $2.4 .2020-15.4 .2020$ & general adult & $\approx 1000$ & $73.0 \%$ & $(60)$ \\
\hline \multirow[t]{2}{*}{$\mathrm{A}$} & Nigeria & 16.6.2020-20.6.2020 & general adult & 670 & $65.3 \%$ & $(58)$ \\
\hline & Nigeria & 2nd-3rd week of lockdown & general adult & 589 & $29.0 \%$ & $(89)$ \\
\hline $\mathrm{A}$ & Poland & $16.6 .2020-20.6 .2020$ & general adult & 666 & $56.3 \%$ & $(58)$ \\
\hline $\mathrm{B}$ & Portugal & $2.4 .2020-15.4 .2020$ & general adult & $\approx 1000$ & $75.0 \%$ & $(60)$ \\
\hline \multirow[t]{2}{*}{ A } & Russia & $16.6 .2020-20.6 .2020$ & general adult & 680 & $54.8 \%$ & $(58)$ \\
\hline & Saudi Arabia & N/A & general adult & 992 & $64.7 \%$ & $(90)$ \\
\hline $\mathrm{A}$ & Singapore & 16.6.2020-20.6.2020 & general adult & 655 & $67.9 \%$ & $(58)$ \\
\hline $\mathrm{A}$ & South Africa & 16.6.2020-20.6.2020 & general adult & 619 & $81.6 \%$ & $(58)$ \\
\hline $\mathrm{A}$ & South Korea & 16.6.2020-20.6.2020 & general adult & 752 & $79.8 \%$ & $(58)$ \\
\hline $\mathrm{F}$ & Spain & April-May 2020 & general adult & 700 & $79.7 \%$ & $(87)$ \\
\hline $\mathrm{A}$ & Spain & 16.6.2020-20.6.2020 & general adult & 748 & $74.4 \%$ & $(58)$ \\
\hline $\mathrm{A}$ & Sweden & 16.6.2020-20.6.2020 & general adult & 650 & $65.2 \%$ & $(58)$ \\
\hline \multirow[t]{5}{*}{$\mathrm{G}$} & Turkey & May 2020 & general adult & 3936 & $66.0 \%$ & $(91)$ \\
\hline & Turkey & $10.6 .2020-10.7 .2020$ & general adult & 759 & $55.5 \%$ & $(92)$ \\
\hline & Turkey & 17.9.2020-20.9.2020 & hcw & 1138 & $68.6 \%$ & (93) \\
\hline & United Arab Emirates & $4.7 .2020-4.8 .2020$ & general adult & 1109 & $22.1 \%$ & $(94)$ \\
\hline & United Kingdom & $1.4 .2020-10.4 .2020$ & older adults (mean 59.5 years of age) & 527 & $85.6 \%$ & $(95)$ \\
\hline \multirow[t]{3}{*}{$\mathrm{B}$} & United Kingdom & $2.4 .2020-15.4 .2020$ & general adult & $\approx 1000$ & $79.0 \%$ & $(60)$ \\
\hline & United Kingdom (England) & $19.4 .2020-11.5 .2020$ & $\begin{array}{c}\text { parents and guardians above } 16 \\
\text { years of age }\end{array}$ & 1252 & $90.1 \%$ & $(96)$ \\
\hline & United Kingdom (England) & $4.5 .2020-11.5 .2020$ & general adult & 2501 & $69.6 \%$ & $(97)$ \\
\hline $\mathrm{F}$ & United Kingdom & 11.05 .2020 & general adult & 1150 & $78.7 \%$ & $(87)$ \\
\hline G & United Kingdom & May 2020 & general adult & 1088 & $83.0 \%$ & $(92)$ \\
\hline \multirow[t]{7}{*}{$\mathrm{A}$} & United Kingdom & 16.6.2020-20.6.2020 & general adult & 768 & $71.5 \%$ & $(58)$ \\
\hline & United Kingdom & $14.7 .2020-17.7 .2020$ & general adult & 1500 & $64.0 \%$ & $(98)$ \\
\hline & United Kingdom & 24.9.2020-17.10.2020 & general adult & 5114 & $71.7 \%$ & $(99)$ \\
\hline & USA & $13.4 .2020-14.4 .2020$ & general adult & 845 & $85.8 \%$ & $(100)$ \\
\hline & USA & 16.4.2020-20.4.2020 & general adult & 991 & $57.6 \%$ & $(101)$ \\
\hline & USA & April 2020 & general adult & 113 & $74.1 \%$ & $(102)$ \\
\hline & USA & April 2020 & general adult & 2233 & $75.5 \%$ & (103) \\
\hline \multirow[t]{5}{*}{$\mathrm{F}$} & USA & April-May 2020 & general adult & 700 & $74.6 \%$ & $(87)$ \\
\hline & USA & 4.5.2020-11.5.2020 & general adult & 3159 & $66.2 \%$ & $(104)$ \\
\hline & USA & $6.5 .2020-19.5 .2020$ & general adult & 1772 & $75.0 \%$ & (59) \\
\hline & USA & May 2020 & general adult & 2006 & $69.0 \%$ & $(105)$ \\
\hline & USA & May 2020 & general adult & 672 & $67.0 \%$ & $(52)$ \\
\hline \multirow[t]{6}{*}{$\mathrm{A}$} & USA & 16.6.2020-20.6.2020 & general adult & 773 & $75.4 \%$ & $(58)$ \\
\hline & USA & July 2020 & general adult & 788 & $59.9 \%$ & $(106)$ \\
\hline & USA & 14.9.2020-27.9.2020 & general adult & 2730 & $61.4 \%$ & $(107)$ \\
\hline & USA & $14.11 .2020-17.11 .2020$ & $\begin{array}{l}\text { hcw (nursing home staff including } \\
\text { administrative and other staff) }\end{array}$ & 8243 & $69.2 \%$ & (108) \\
\hline & USA & N/A & $\begin{array}{c}\text { general adult ( } 7 \text { participants below } \\
18 \text { years of age) }\end{array}$ & 316 & $68.6 \%$ & (109) \\
\hline & USA & N/A & university students (medical students) & 167 & $77.0 \%$ & $(110)$ \\
\hline
\end{tabular}

$\mathrm{wtp}=$ the study assessed willingness to pay for a vaccine against COVID-19, A, B, C, D, E, F, G - studies monitoring COVID-19 vaccine acceptance in different countries with results published in one study, hcw = healthcare workers, $\mathrm{N} / \mathrm{A}=$ not available 


\section{8-547}

where the survey was conducted, time of the survey, population (mainly general adult population, healthcare workers and university students), sample size and percentage of people interested in receiving a vaccine against COVID-19.

The scales for assessment of COVID-19 vaccine acceptance differed across the articles. Some studies offered just dichotomous Yes/No choice forcing the respondents to take a clear stand whereas other used multi-point Likert scales with possibility of "I do not know" or "Neutral" answer. For purpose of this work we dichotomized the answers to vaccine acceptance group ("Yes", "Very likely", "Likely", "Leaning towards yes" and similar answers) and vaccine hesitant group ("No", "Definitely not", "Unlikely", "Leaning towards no" and similar answers and also "Neutral" and "I do not know" answers).

\section{Statistical analysis}

The relations between the willingness to take COVID-19 vaccine (\% of acceptance) and several parameters were statistically analysed. The parameters that were correlated with COVID-19 vaccine acceptance rate encompassed number of cases per million and number of deaths per million at the time of conduction of particular survey, number of beds per thousand in particular country, duration of pandemic, GDP (gross domestic product) per capita and HDI (human development index). The correlations were evaluated by Spearman's correlation coefficient. The data were acquired at https:// ourworldindata.org/ (30). We assessed all data all together and then healthcare workers (including healthcare students) and general population (including non-healthcare students) separately. The level of significance $(\mathrm{P}<0.05)$ was used for all performed tests. The analysis included only articles from which complete data (all parameters) could be obtained. Statistically significant results are marked directly in Figure 3 by an asterisk (*). We used following scale: ${ }^{*} \mathrm{p}$ $<0.05, * *$ for $\mathrm{p}<0.01, * * *$ for $\mathrm{p}<0.001$ and $* * * *$ for $\mathrm{p}<0.0001$. All calculations were performed with GraphPad Prism 8 software.

\section{Results}

\section{PRISMA 2009 Flow Diagram}

We identified 451 articles in PubMed ${ }^{\circledR}, 296$ articles in Web of Science and 435 articles in Scopus database giving a total of 1182 manuscripts. After removing duplicities (Mendeley Desktop software) we received a total count of 584 articles. Additional searching revealed other 7 relevant articles ( 6 from GoogleScholar and 1 from other source (31)) giving a total of 591 manuscripts assessed for their eligibility. At the first level of eligibility assessment 439 articles were excluded. After full-text analysis (second level of eligibility assessment) another 90 articles were excluded resulting in a total of 62 manuscripts included in the analysis. PRISMA Flow Diagram is shown in Figure 1.

\section{Identified studies}

The surveys were conducted in 40 countries (most of the surveys were conducted in United States of America, United Kingdom, Italy, China and Germany). Total sample size was 118855 respondents with overall average COVID-19 vaccine acceptance rate of $72.5 \%$. The overall average COVID-19 vaccine acceptance rate was calculated as a sum of multiples of number of respondents and acceptance rate in each study all divided by total number of respondents.

Summary of all 62 identified studies is shown in Table 1.

Figure 2 shows COVID-19 vaccine acceptance rates in particular countries. In case of more studies conducted in one country we calculated the overall average of COVID-19 vaccine acceptance rate reported by all studies in particular country.

The surveys were mostly conducted among general adult population. Several studies were conducted either among healthcare workers or among university students. Total sample sizes with overall average COVID-19 vaccine acceptance rates among these groups are shown in Table 2.

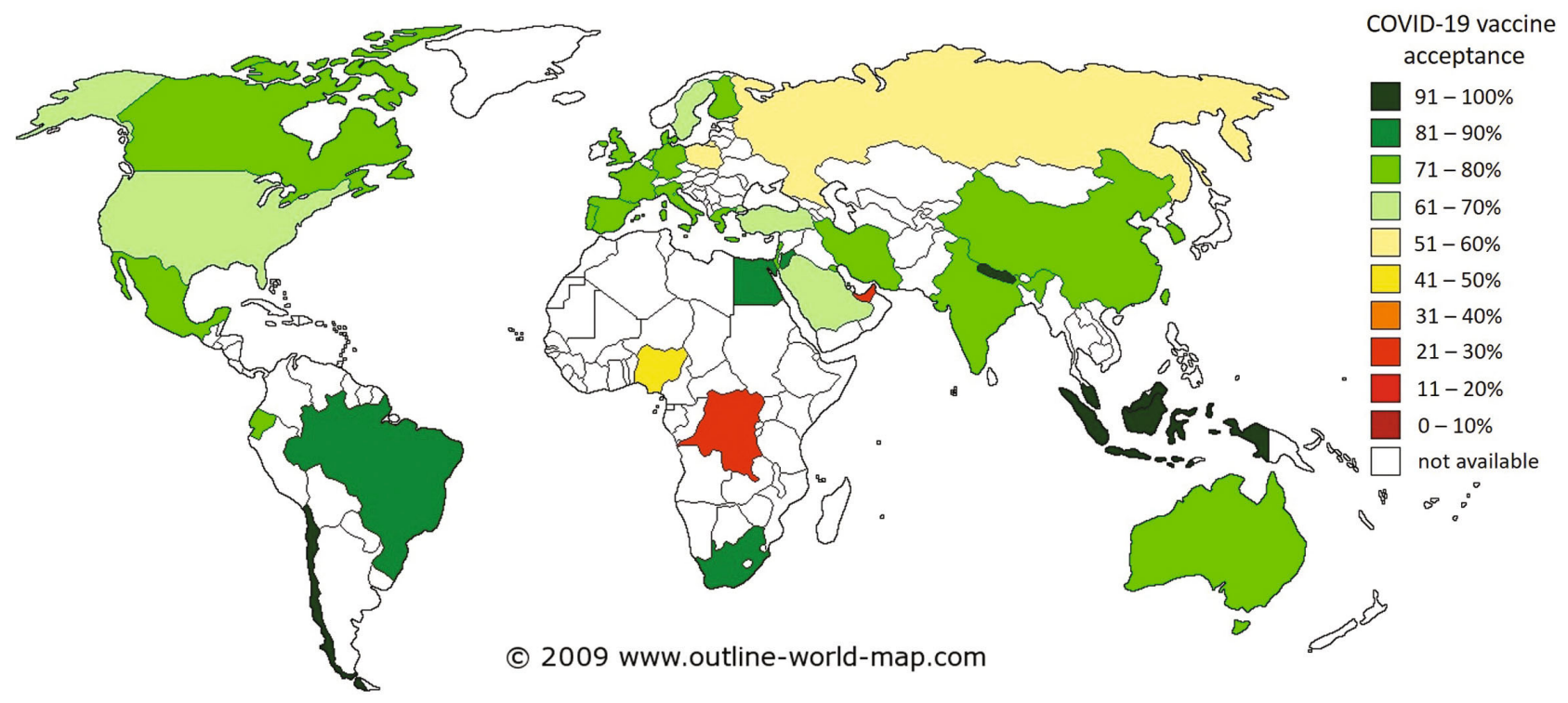

Fig. 2. COVID-19 vaccine acceptance rates worldwide. 
Tab. 2. COVID-19 vaccine acceptance rates among general adult population, healthcare workers and university students.

\begin{tabular}{lcc}
\hline & $\begin{array}{c}\text { Total sample } \\
\text { size }\end{array}$ & $\begin{array}{c}\text { COVID-19 vaccine acceptance } \\
\text { rate (overall average) }\end{array}$ \\
\hline General adult population & 95232 & $73.0 \%$ \\
Healthcare workers & 19457 & $69.2 \%$ \\
University students & 4166 & $76.9 \%$ \\
\hline
\end{tabular}

\section{Statistical analysis}

All obtained correlation coefficients and corresponding $\mathrm{p}$ are shown in Figure 3. We found weak, but statistically significant negative correlation between number of cases per million, deaths per million, beds per thousand, duration of pandemic and acceptance of COVID-19 vaccine in total population. There was no significant relation between acceptance of COVID-19 vaccine and economic parameters (GDP per capita and HDI) of particular country.

When the data were assessed according to population surveyed (i.e. healthcare workers including healthcare students and general population), the results differed. We did not find any significant relation between acceptance of COVID-19 vaccine and all parameters in group of healthcare workers. In general population, Spearman's coefficients showed similar trend as in total population but the correlation was slightly stronger. We found moderate negative correlation between acceptance of COVID-19 vaccine and number of cases per million and duration of pandemic. Moreover, there was weak negative correlation for vaccine acceptance and GDP per capita. On the contrary to total population, there was no significant relation between vaccine acceptance and number of beds per thousand.

\section{Discussion}

According to official WHO webpage until February 26, 2021 COVID-19 spread into 223 countries, infected 112649371 people and caused death of 2501229 people (32). The level of immune

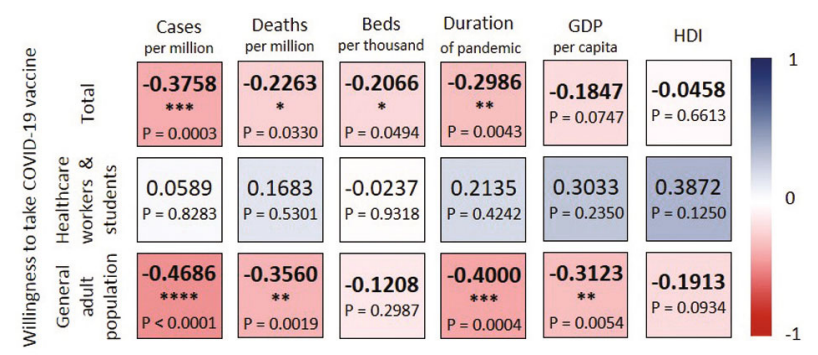

Fig. 3. Relations between acceptance of COVID-19 vaccine and following parameters: number of cases per million in time of conduction of surveys, number of deaths per million in time of conduction of surveys, number of beds per thousand in particular country, duration of pandemic, GDP per capita and HDI. The relations were evaluated by Spearman's correlation coefficient at level of significance $p<0.05$. We evaluated all data all together $(n=89)$ and then healthcare workers (including healthcare students; $n=16$ ) and general population (including non-healthcare students; $n=74$ ) separately. Statistically significant results are marked by an asterisk (*). We used following scale: ${ }^{*} \mathbf{p}<\mathbf{0 . 0 5}$, ** for $\mathbf{p}<\mathbf{0 . 0 1}$, *** for $\mathbf{p}<\mathbf{0 . 0 0 1}$ and $* * * *$ for $\mathbf{p}<$ $\mathbf{0 . 0 0 0 1}$. The colour indicates the strength of correlation coefficient. response after COVID-19 infection remains a question. For seasonal coronaviruses the immunity is short-lasting (33). In case of COVID-19 there is an emerging amount of case reports reporting re-infections (34-37). Some of the re-infections may present with milder course of the disease whereas other may develop to more severe health conditions (38). Moreover, there is no evidence that Swedish strategy in managing COVID-19 by attempting for herd immunity by not implementing strong restrictive regulations would be successful $(39,40)$. Thus, the main hope for managing COVID-19 pandemic is vaccination.

If the proportion of the population that is immune (by vaccination or natural infection) exceeds certain level the incidence of the disease will start to decline. This is known as the "herd immunity threshold" and arises because a subset of the susceptible population benefits from "indirect protection" by the immunization of individuals that surround them (41). Vaccination programs help mankind to control the incidence of many infectious diseases based on two main principles: 1) directly through protection of an individual by building up the immune response and 2) indirectly by providing herd immunity for those who cannot be vaccinated. Many examples of indirect protection have been described (42).

In 2020 scientists, universities and pharmaceutical companies raced to develop an efficient and safe vaccine against COVID-19. At the end of 2020 and in early 2021 many countries started to vaccinate their citizens against COVID-19. Vaccination rate providing herd immunity in case of COVID-19 is estimated to be around $70 \%(43,44)$. In this review we covered COVID-19 vaccine acceptance rates reported in peer-reviewed manuscripts worldwide.

Surveys from 40 countries with a total sample size of 118855 respondents were identified with overall average acceptance rate of $72.5 \%$. Most of the countries showed COVID-19 vaccine acceptance rate higher than $61 \%$ (Fig. 2). However, several surprising and striking results were revealed.

In total population, our analysis showed that the intention to be vaccinated against COVID-19 decreased over time (negative correlation coefficient in case of duration of the pandemic). The longer the pandemic lasted (i.e. the later the survey was conducted), the smaller proportion of people was willing to be vaccinated. This phenomenon may also explain decreasing willingness to be vaccinated with increasing number of total cases and deaths per million (Fig. 3). In accordance with our analysis there are several reports showing similar trends (45-47). On the contrary to the parameters related to severity and duration of the pandemic, there was no correlation found between the intention to be vaccinated and degree of development of particular country (GDP per capita or HDI).

The COVID-19 vaccine acceptance rate was surprisingly lower in healthcare workers than in general adult population and students (Tab. 2). This result is affected by several studies carried out in Congo, Greece, Malta and China which showed COVID-19 vaccine acceptance far below $60 \%(48-51)$. When potential relations between willingness to take COVID-19 vaccine and monitored parameters are evaluated separately in general adult population and healthcare workers (and students), there are several differences in the attitudes between these two groups. Although the acceptance of COVID-19 vaccine is lower in healthcare workers, 
none of the factors correlated with COVID-19 vaccine acceptance rate affected their willingness to be vaccinated. On the contrary to healthcare workers, in the general adult population the obtained results showed similar trend as in total population but with slightly stronger correlation coefficients, i.e. willingness to get COVID-19 vaccine decreased over time. We also found a statistically significant negative correlation between acceptance of vaccine and GDP per capita in general adult population.

Several reviews of surveys monitoring people's willingness to be vaccinated against COVID-19 have already been published either after full peer-review process or in the form of a preprint (52-55). However, to the best of our knowledge these studies either included in the analysis also non-peer-reviewed source of data or have identified considerably smaller number of peer-reviewed manuscripts.

If the interest of people to receive a COVID-19 vaccine follows current trend and decreases further, the vaccination rate may not achieve herd immunity threshold. This may result in necessity of implementation of legislative measures making COVID-19 vaccination compulsory in future.

Moreover, current vaccines may not protect against future mutations. Thus, ongoing surveillance of new mutations and prompt improvements (potentially requiring other emergency use authorizations) of the vaccines may be needed to manage the pandemic efficiently.

\section{Conclusion}

Vaccination is considered to be the most promising way of managing COVID-19 pandemic. The interest of people in being vaccinated against COVID-19 is "just" at the level of estimated herd immunity threshold. However, the willingness to be vaccinated is decreasing with increasing time of the pandemic. Surprisingly, interest of healthcare workers in receiving COVID-19 vaccine is smaller than in general adult population and students. On the contrary to general population, healthcare workers (and healthcare students) do not change their attitude to COVID-19 vaccine over time and their attitude to COVID-19 vaccine is not affected by any of the monitored parameters.

\section{References}

1. Riedel S. Edward Jenner and the history of smallpox and vaccination. Proceedings Baylor Univ Med Center 2005; 18 (1): 21-25.

2. Lombard M, Pastoret PP, Moulin AM. A brief history of vaccines and vaccination. Rev Sci Techn (International Office of Epizootics) 2007; 26 (1): 29-48.

3. Plotkin S. History of vaccination. Proc Nat Acad Sci US Amer 2014; 111 (34): 12283-12287.

4. Breman JG, Arita I. The confirmation and maintenance of smallpox eradication. New Engl J Med 1980; 303 (22): 1263-1273.

5. Larson HJ, Jarrett C, Eckersberger E, Smith DM, Paterson P. Understanding vaccine hesitancy around vaccines and vaccination from a global perspective: a systematic review of published literature, 2007-2012. Vaccine 2014; 32 (19): 2150-2159.
6. Organization WH. Ten threats to global health in 2019 [Available from: https://www.who.int/news-room/spotlight/ten-threats-to-globalhealth-in-2019.

7. MacDonald NE. Vaccine hesitancy: Definition, scope and determinants. Vaccine 2015; 33 (34): 4161-4164.

8. Ye C, Zhu W, Yu J, Li Z, Hu W, Hao L et al. Low coverage rate and awareness of influenza vaccine among older people in Shanghai, China: A cross-sectional study. Human Vaccines Immunother 2018; 14 (11): 2715-2721.

9. Lèfevre H, Schrimpf C, Moro M, Lachal J. HPV vaccination rate in French adolescent girls: an example of vaccine distrust. Arch Dis Childhood 2017; 103: 740 - 746.

10. Fan J, Cong S, Wang N, Lyu XL, Bao HL, Wang BH et al. Pneumococcal vaccination rate in chronic obstructive pulmonary disease patients aged 40 years or older in China, 2014-2015. Zhonghua liu xing bing xue za zhi = Zhonghua liuxingbingxue zazhi 2020; 41 (7): 1028-1033.

\section{Chlíbek R. Očkování dospělých: Mladá fronta; 2019.}

12. Ozisik L, Tanriover MD, Rigby S, Unal S. ADVICE for a healthier life: Adult Vaccination Campaign in Europe. Eur J Intern Med 2016; 33 : 14-20.

13. Prevention CfDCa. Healthy People 20202020 [Available from: https://www.cdc.gov/nchs/healthy_people/hp2020.htm.

14. Organization WH. Vaccines and immunization: What is vaccination? [Available from: https://www.who.int/news-room/q-a-detail/vaccines-andimmunization-what-is-vaccination? adgroupsurvey $=\%$ 7badgroupsurvey $\%$ 7d\&gclid=EAIaIQobChMI3qS7xsmd7gIVh5iyCh0HygByEAAYASAAE gI6U_D_BwE.

15. Prevention CfDCa. There Are Vaccines You Need as an Adult [Available from: https://www.cdc.gov/vaccines/adults/index.html.

16. Organization WH. Coronavirus desease 2019 (COVID-19) Situation Report [Available from: https://www.who.int/docs/defaultsource/coronaviruse/situation-reports/20200311-sitrep-51-covid-19. pdf?sfvrsn=1ba62e57_10.

17. Rodriguez-Morales AJ, Cardona-Ospina JA, Gutiérrez-Ocampo E, Villamizar-Peña R, Holguin-Rivera Y, Escalera-Antezana JP et al. Clinical, laboratory and imaging features of COVID-19: A systematic review and meta-analysis. Travel Med Infect Dis 2020; 34: 101623.

18. Sohrabi C, Alsafi Z, O'Neill N, Khan M, Kerwan A, Al-Jabir A et al. World Health Organization declares global emergency: A review of the 2019 novel coronavirus (COVID-19). Internat J Surg 2020; 76: 71-76.

19. Lopez M, Bell K, Annaswamy T, Juengst S, Ifejika N. COVID-19 Guide for the Rehabilitation Clinician: A Review of Nonpulmonary Manifestations and Complications. Amer J Phys Med Rehab 2020; 99 (8): 669-673.

20. Chen X, Laurent S, Onur OA, Kleineberg NN, Fink GR, Schweitzer F et al. A systematic review of neurological symptoms and complications of COVID-19. J Neurol 2020: 1-11.

21. Kunutsor SK, Laukkanen JA. Renal complications in COVID-19: a systematic review and meta-analysis. Ann Med 2020; 52 (7): 345-353.

22. Kunutsor SK, Laukkanen JA. Hepatic manifestations and complications of COVID-19: A systematic review and meta-analysis. J Infect 2020; 81 (3): e72-e4.

23. Aghagoli G, Gallo Marin B, Soliman LB, Sellke FW. Cardiac involvement in COVID-19 patients: Risk factors, predictors, and complications: A review. J Cardiac Surg 2020; 35 (6): 1302-1305. 
24. Terpos E, Ntanasis-Stathopoulos I, Elalamy I, Kastritis E, Sergentanis TN, Politou M et al. Hematological findings and complications of COVID-19. Amer J Hematol 2020; 95 (7): 834-847.

25. Disser NP, De Micheli AJ, Schonk MM, Konnaris MA, Piacentini AN, Edon DL et al. Musculoskeletal Consequences of COVID-19. J Bone Joint Surg Amer 2020; 102 (14): 1197-1204.

26. Wong SH, Lui RN, Sung JJ. Covid-19 and the digestive system. J Gastroenterol Hepatol 2020; 35 (5): 744-748.

27. Sanders JM, Monogue ML, Jodlowski TZ, Cutrell JB. Pharmacologic Treatments for Coronavirus Disease 2019 (COVID-19): A Review. JAMA 2020; 323 (18): 1824-1836.

28. Tuite AR, Zhu L, Fisman DN, Salomon JA. Alternative Dose Allocation Strategies to Increase Benefits From Constrained COVID-19 Vaccine Supply. Ann Intern Med 2021.

29. Moher D, Liberati A, Tetzlaff J, Altman DG. Preferred reporting items for systematic reviews and meta-analyses: the PRISMA statement. PLoS medicine 2009; 6 (7): e1000097.

30. Ritchie H. Coronavirus Source Data [Available from: https://ourworldindata.org/coronavirus-source-data.

31. Sallam M. COVID-19 vaccine hesitancy worldwide: a systematic review of vaccine acceptance rates. medRxiv 2021:2020.12.28.20248950.

32. Organization” WH. Coronavirus desease (COVID-19) pandemic [Available from: https://www.who.int/emergencies/diseases/novel-coronavirus-2019? gclid=EAIaIQobChMIvozwn9Gn7gIVjLmyCh0jig4IEAA YASAAEgLNefD_BwE.

33. Edridge AWD, Kaczorowska J, Hoste ACR, Bakker M, Klein M, Loens $\mathrm{K}$ et al. Seasonal coronavirus protective immunity is short-lasting. Nature Med 2020; 26 (11): 1691-1693.

34. Duggan NM, Ludy SM, Shannon BC, Reisner AT, Wilcox SR. Is novel coronavirus 2019 reinfection possible? Interpreting dynamic SARSCoV-2 test results. Amer J Emerg Med 2021; 39: 256.e1-.e3.

35. Bonifácio LP, Pereira APS, Araújo D, Balbão V, Fonseca B, Passos ADC et al. Are SARS-CoV-2 reinfection and Covid-19 recurrence possible? a case report from Brazil. Rev Soc Brasil Med Trop 2020; 53 : e20200619.

36. Torres DA, Ribeiro L, Riello A, Horovitz DDG, Pinto LFR, Croda J. Reinfection of COVID-19 after 3 months with a distinct and more aggressive clinical presentation: Case report. J Med Virol 2020.

37. Hanif M, Haider MA, Ali MJ, Naz S, Sundas F. Reinfection of COVID-19 in Pakistan: A First Case Report. Cureus 2020; 12 (10): e11176.

38. Iwasaki A. What reinfections mean for COVID-19. Lancet Infect Dis 2021; 21 (1): 3-5.

39. Orlowski EJW, Goldsmith DJA. Four months into the COVID-19 pandemic, Sweden's prized herd immunity is nowhere in sight. J Royal Soc Med 2020; 113 (8): 292-298.

40. Habib H. Has Sweden's controversial covid-19 strategy been successful? BMJ 2020; 369: m2376.

41. Metcalf CJE, Ferrari M, Graham AL, Grenfell BT. Understanding Herd Immunity. Trends Immunol 2015; 36 (12): 753-735.

42. Fine P, Eames K, Heymann DL. "Herd immunity": a rough guide. Clin Infect Dis 2011; 52 (7): 911-916.

43. Kadkhoda K. Herd Immunity to COVID-19: Alluring and Elusive. Amer J Clin Pathol 2021.
44. Fontanet A, Cauchemez S. COVID-19 herd immunity: where are we? Nature Rev Immunol 2020; 20 (10): 583-584.

45. Szilagyi PG, Thomas K, Shah MD, Vizueta N, Cui Y, Vangala S et al. National Trends in the US Public's Likelihood of Getting a COVID-19 Vaccine-April 1 to December 8, 2020. JAMA 2020.

46. Daly M, Robinson E. Willingness to vaccinate against COVID-19 in the US: Longitudinal evidence from a nationally representative sample of adults from April-October 2020. medRxiv 2020:2020.11.27.20239970.

47. Lin Y, Hu Z, Zhao Q, Alias H, Danaee M, Wong LP. Understanding COVID-19 vaccine demand and hesitancy: A nationwide online survey in China. PLoS Neglected Trop Dis 2020; 14 (12): e0008961.

48. Kabamba Nzaji M, Kabamba Ngombe L, Ngoie Mwamba G, Banza Ndala DB, Mbidi Miema J, Luhata Lungoyo C et al. Acceptability of Vaccination Against COVID-19 Among Healthcare Workers in the Democratic Republic of the Congo. Pragmatic Observat Res 2020; 11: 103-109.

49. Papagiannis D, Malli F, Raptis DG, Papathanasiou IV, Fradelos EC, Daniil Z et al. Assessment of Knowledge, Attitudes, and Practices towards New Coronavirus (SARS-CoV-2) of Health Care Professionals in Greece before the Outbreak Period. Internat J Environ Res Publ Health 2020; 17: 14.

50. Wang K, Wong ELY, Ho KF, Cheung AWL, Chan EYY, Yeoh EK et al. Intention of nurses to accept coronavirus disease 2019 vaccination and change of intention to accept seasonal influenza vaccination during the coronavirus disease 2019 pandemic: A cross-sectional survey. Vaccine 2020; 38 (45): 7049-7056.

51. Grech V, Gauci C, Agius S. Vaccine hesitancy among Maltese healthcare workers toward influenza and novel COVID-19 vaccination. Early Human Develop 2020:105213.

52. Malik AA, McFadden SM, Elharake J, Omer SB. Determinants of COVID-19 Vaccine Acceptance in the U.S. medRxiv 2020:2020.05.22.20110700.

53. Lin C, Tu P, Beitsch LM. Confidence and Receptivity for COVID-19 Vaccines: A Rapid Systematic Review. Vaccines 2020; 9 (1).

54. Robinson E, Jones A, Lesser I, Daly M. International estimates of intended uptake and refusal of COVID-19 vaccines: A rapid systematic review and meta-analysis of large nationally representative samples. medRxiv 2020:2020.12.01.20241729.

55. Marcec R, Majta M, Likic R. Will vaccination refusal prolong the war on SARS-CoV-2? Postgrad Med J 2020.

56. Ali KF, Whitebridge S, Jamal MH, Alsafy M, Atkin SL. Perceptions, Knowledge, and Behaviors Related to COVID-19 Among Social Media Users: Cross-Sectional Study. J Med Internet Res 2020; 22 (9): e19913.

57. Faasse K, Newby J. Public perceptions of COVID-19 in Australia: perceived risk, knowledge, health-protective behaviours, and vaccine intentions. medRxiv 2020:2020.04.25.20079996.

58. Lazarus JV, Ratzan SC, Palayew A, Gostin LO, Larson HJ, Rabin K et al. A global survey of potential acceptance of a COVID-19 vaccine. Nature Med 2020: 1-4.

59. Taylor S, Landry CA, Paluszek MM, Groenewoud R, Rachor GS, Asmundson GJG. A Proactive Approach for Managing COVID-19: The Importance of Understanding the Motivational Roots of Vaccination Hesitancy for SARS-CoV2. Front Psychol 2020; 11 (2890).

60. Neumann-Böhme S, Varghese NE, Sabat I, Barros PP, Brouwer W, van Exel J et al. Once we have it, will we use it? A European survey on willingness to be vaccinated against COVID-19. Eur J Health Econom 2020; 21 (7): 977-982. 
61. Sarasty O, Carpio CE, Hudson D, Guerrero-Ochoa PA, Borja I. The demand for a COVID-19 vaccine in Ecuador. Vaccine 2020; 38 (51): 8090-8098.

62. Abdelhafiz AS, Mohammed Z, Ibrahim ME, Ziady HH, Alorabi M, Ayyad $\mathbf{M}$ et al. Knowledge, Perceptions, and Attitude of Egyptians Towards the Novel Coronavirus Disease (COVID-19). J Comm Health 2020; 45 (5): 881-890.

63. Karlsson LC, Soveri A, Lewandowsky S, Karlsson L, Karlsson H, Nolvi S et al. Fearing the disease or the vaccine: The case of COVID-19. Personal Individual Diff 2021; 172: 110590

64. Detoc M, Bruel S, Frappe P, Tardy B, Botelho-Nevers E, GagneuxBrunon A. Intention to participate in a COVID-19 vaccine clinical trial and to get vaccinated against COVID-19 in France during the pandemic. Vaccine 2020; 38 (45): 7002-7006.

65. Gagneux-Brunon A, Detoc M, Bruel S, Tardy B, Rozaire O, Frappe P et al. Intention to get vaccinations against COVID-19 in French healthcare workers during the first pandemic wave: a cross sectional survey. J Hosp Infection 2020; 108: 168-173.

66. Paffenholz P, Peine A, Hellmich M, Paffenholz SV, Martin L, Luedde $\mathbf{M}$ et al. Perception of the 2020 SARS-CoV-2 pandemic among medical professionals in Germany: results from a nationwide online survey. Emerging Microbes Infect 2020; 9 (1): 1590-1599.

67. Grüner S, Krüger $\mathbf{F}$. The intention to be vaccinated against COVID-19: stated preferences before vaccines were available. Appl Econom Lett 2020: 1-5.

68. Mouchtouri VA, Agathagelidou E, Kofonikolas K, Rousou X, Dadouli K, Pinaka $\mathbf{O}$ et al. Nationwide Survey in Greece about Knowledge, Risk Perceptions, and Preventive Behaviors for COVID-19 during the General Lockdown in April 2020. Internat J Environmen Res Publ Health 2020; 17 (23).

69. García LY, Cerda AA. Contingent assessment of the COVID-19 vaccine. Vaccine 2020; 38: 5424 - 5429.

70. Jiang R. Knowledge, attitudes and mental health of university students during the COVID-19 pandemic in China. Child Youth Servic Rev 2020; 119: 105494.

71. Kwok KO, Li KK, Wei WI, Tang A, Wong SYS, Lee SS. Editor's Choice: Influenza vaccine uptake, COVID-19 vaccination intention and vaccine hesitancy among nurses: A survey. Internat J Nursing Studies 2021; 114: 103854

72. Wang J, Jing R, Lai X, Zhang H, Lyu Y, Knoll MD et al. Acceptance of COVID-19 Vaccination during the COVID-19 Pandemic in China. Vaccines 2020; 8 (3).

73. Khan S, Rahman CKF, C V H, Jose B, Tiwari R, Dhama K. COVID-19 Vaccine Acceptance: Beliefs and Barriers Associated with Vaccination Among the General Population in India. J Exp Biol Agricult Sci 2020; 8: S210-S218.

74. Harapan H, Wagner AL, Yufika A, Winardi W, Anwar S, Gan AK et al. Willingness-to-pay for a COVID-19 vaccine and its associated determinants in Indonesia. Human Vaccines Imunother 2020; 16 (12): 3074-3080.

75. Kakemam E, Ghoddoosi-Nejad D, Chegini Z, Momeni K, Salehiniya $\mathbf{H}$, Hassanipour $\mathbf{S}$ et al. Knowledge, Attitudes, and Practices Among the General Population During COVID-19 Outbreak in Iran: A National Cross-Sectional Online Survey. Front Publ Health 2020; 8: 585302.

76. Dror AA, Eisenbach N, Taiber S, Morozov NG, Mizrachi M, Zigron $\mathbf{A}$ et al. Vaccine hesitancy: the next challenge in the fight against COVID-19. Eur J Epidemiol 2020; 35 (8): 775-779.
77. Vai B, Cazzetta S, Ghiglino D, Parenti L, Saibene G, Toti M et al. Risk Perception and Media in Shaping Protective Behaviors: Insights From the Early Phase of COVID-19 Italian Outbreak. Front Psychol 2020; 11: 563426.

78. Prati G. Intention to receive a vaccine against SARS-CoV-2 in Italy and its association with trust, worry and beliefs about the origin of the virus. Health Educ Res 2020; 35 (6): 505-511.

79. Graffigna G, Palamenghi L, Boccia S, Barello S. Relationship between Citizens' Health Engagement and Intention to Take the COVID-19 Vaccine in Italy: A Mediation Analysis. Vaccines 2020; 8 (4).

80. Biasio LR, Bonaccorsi G, Lorini C, Pecorelli S. Assessing COVID-19 vaccine literacy: a preliminary online survey. Human Vaccines Immunother 2020: 1-9.

81. Barello S, Nania T, Dellafiore F, Graffigna G, Caruso R. 'Vaccine hesitancy' among university students in Italy during the COVID-19 pandemic. Eur J Epidemiol 2020; 35 (8): 781-783.

82. La Vecchia C, Negri E, Alicandro G, Scarpino V. Attitudes towards influenza vaccine and a potential COVID-19 vaccine in Italy and differences across occupational groups, September 2020. La Medicina del lavoro 2020; 111 (6): 445-448.

83. Al-Azzam N, Elsalem L, Gombedza F. A cross-sectional study to determine factors affecting dental and medical students' preference for virtual learning during the COVID-19 outbreak. Heliyon 2020; 6 (12): e05704.

84. Wong LP, Alias H, Wong P-F, Lee HY, AbuBakar S. The use of the health belief model to assess predictors of intent to receive the COVID-19 vaccine and willingness to pay. Human Vaccines Immunother 2020; 16 (9): 2204-2214

85. Grech V, Gauci C. Vaccine hesitancy in the University of Malta Faculties of Health Sciences, Dentistry and Medicine vis-à-vis influenza and novel COVID-19 vaccination. Early Human Develop 2020: 105258.

86. Grech V, Bonnici J, Zammit D. Vaccine hesitancy in Maltese family physicians and their trainees vis-à-vis influenza and novel COVID-19 vaccination. Early Human Develop 2020: 105259.

87. Roozenbeek J, Schneider CR, Dryhurst S, Kerr J, Freeman ALJ, Recchia G et al. Susceptibility to misinformation about COVID-19 around the world. Royal Soc Open Sci 2020; 7 (10): 201199.

88. Parajuli J, Mishra P, Sharma S, Bohora KB, Rathour PS, Joshi J et al. Knowledge and Attitude about COVID 19 among Health Care Workers Working in Seti Provincial Hospital. J Nepal Health Res Council 2020; 18 (3): 466-471.

89. Reuben RC, Danladi MMA, Saleh DA, Ejembi PE. Knowledge, Attitudes and Practices Towards COVID-19: An Epidemiological Survey in North-Central Nigeria. J Comm Health 2020: 1-14.

90. Al-Mohaithef M, Padhi BK. Determinants of COVID-19 Vaccine Acceptance in Saudi Arabia: A Web-Based National Survey. J Multidiscip Healthcare 2020; 13: 1657-1663.

91. Salali GD, Uysal MS. COVID-19 vaccine hesitancy is associated with beliefs on the origin of the novel coronavirus in the UK and Turkey. Psychol Med 2020: 1-3.

92. Akarsu B, Canbay Özdemir D, Ayhan Baser D, Aksoy H, Fidanci I, Cankurtaran M. While studies on COVID-19 vaccine is ongoing, the public's thoughts and attitudes to the future COVID-19 vaccine. Internat J Clin Practice.n/a (n/a): e13891.

93. Kose S, Mandiracioglu A, Sahin S, Kaynar T, Karbus O, Ozbel Y. Vaccine hesitancy of the COVID-19 by health care personnel. International Journal of Clinical Practice.n/a (n/a): e13917. 
94. Muqattash R, Niankara I, Traoret RI. Survey data for COVID-19 vaccine preference analysis in the United Arab Emirates. Data in Brief $2020 ; 33: 106446$

95. Williams L, Gallant AJ, Rasmussen S, Brown Nicholls LA, Cogan $\mathbf{N}$, Deakin $\mathrm{K}$ et al. Towards intervention development to increase the uptake of COVID-19 vaccination among those at high risk: Outlining evidence-based and theoretically informed future intervention content. Brit J Health Psychol 2020; 25 (4): 1039-1054.

96. Bell S, Clarke R, Mounier-Jack S, Walker JL, Paterson P. Parents' and guardians' views on the acceptability of a future COVID-19 vaccine: A multi-methods study in England. Vaccine 2020; 38 (49): 7789-7798.

97. Freeman D, Waite F, Rosebrock L, Petit A, Causier C, East A et al. Coronavirus conspiracy beliefs, mistrust, and compliance with government guidelines in England. Psychol Med 2020: 1-13.

98. Sherman SM, Smith LE, Sim J, Amlôt R, Cutts M, Dasch H et al. COVID-19 vaccination intention in the UK: results from the COVID-19 vaccination acceptability study (CoVAccS), a nationally representative cross-sectional survey. Human Vaccines Immunother 2020: 1-10.

99. Freeman D, Loe BS, Chadwick A, Vaccari C, Waite F, Rosebrock L et al. COVID-19 vaccine hesitancy in the UK: the Oxford coronavirus explanations, attitudes, and narratives survey (Oceans) II. Psychol Med 2020: $1-15$.

100. Earnshaw VA, Eaton LA, Kalichman SC, Brousseau NM, Hill EC, Fox AB. COVID-19 conspiracy beliefs, health behaviors, and policy support. Translat Behav Med 2020; 10 (4): 850-856.

101. Fisher KA, Bloomstone SJ, Walder J, Crawford S, Fouayzi H, Mazor KM. Attitudes Toward a Potential SARS-CoV-2 Vaccine: A Survey of U.S. Adults. Anna Intern Med 2020; 173 (12): 964-973.
102. Hogan C, Atta M, Anderson P, Stead T, Solomon M, Banerjee P et al. Knowledge and attitudes of us adults regarding COVID-19. Internat J Emerg Med 2020; 13 (1): 53.

103. Southwell BG, Kelly BJ, Bann CM, Squiers LB, Ray SE, McCormack LA. Mental Models of Infectious Diseases and Public Understanding of COVID-19 Prevention. Health Comm 2020; 35 (14): 1707-1710.

104. Head KJ, Kasting ML, Sturm LA, Hartsock JA, Zimet GD. A National Survey Assessing SARS-CoV-2 Vaccination Intentions: Implications for Future Public Health Communication Efforts. Sci Comm 2020; 42 (5): 698-723.

105. Reiter PL, Pennell ML, Katz ML. Acceptability of a COVID-19 vaccine among adults in the United States: How many people would get vaccinated? Vaccine 2020; 38 (42): 6500-6507.

106. Guidry JPD, Laestadius LI, Vraga EK, Miller CA, Perrin PB, Burton CW et al. Willingness to get the COVID-19 vaccine with and without emergency use authorization. Amer J Infect Control 2021; 49 (2): 137-142.

107. Largent EA, Persad G, Sangenito S, Glickman A, Boyle C, Emanuel EJ. US Public Attitudes Toward COVID-19 Vaccine Mandates. JAMA Netw Open 2020; 3 (12): e2033324-e.

108. Unroe KT, Evans R, Weaver L, Rusyniak D, Blackburn J. Willingness of Long-Term Care Staff to Receive a COVID-19 Vaccine: A Single State Survey. J Amer Geriatr Soc 2020; n/a (n/a).

109. Pogue K, Jensen JL, Stancil CK, Ferguson DG, Hughes SJ, Mello EJ et al. Influences on Attitudes Regarding Potential COVID-19 Vaccination in the United States. Vaccines 2020; 8 (4): 582.

110. Lucia VC, Kelekar A, Afonso NM. COVID-19 vaccine hesitancy among medical students. J Publ Health (Oxford, England) 2020.

Received February 27, 2021. Accepted March 16, 2021. 